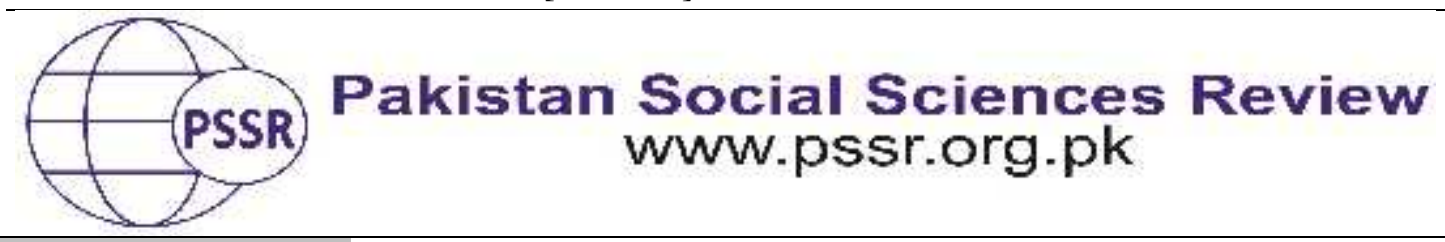

RESEARCH PAPER

\title{
Role of Citizen Participation in Rural Development: A Case Study of Pakistan
}

\author{
Faiz Ur Rahim${ }^{* 1}$ Junaid Hassan Saleem ${ }^{2}$
}

1. Assistant Professor, International Institute of Islamic Economics (IIIE), International Islamic University Islamabad, Pakistan

2. MS Rural Development, International Institute of Islamic Economics (IIIE), International Islamic University Islamabad, Pakistan

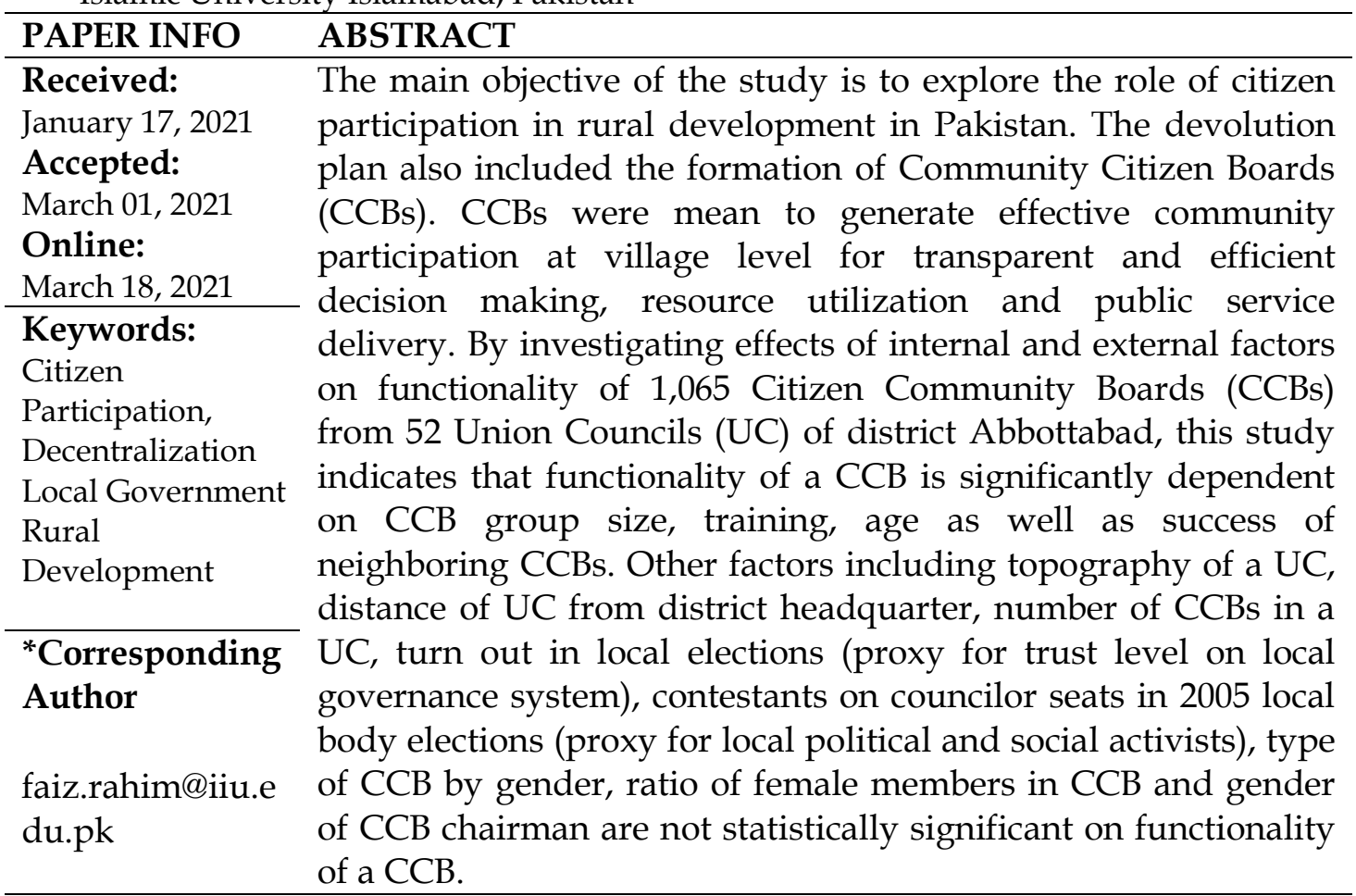

\section{Introduction}

Malfunctioning of governance system is one of common characteristics of developing economies all over the world. This reality exists both at the macro level, i.e., provincial level and at the micro level, across district and lower levels. Severity of this problem increases at district and lower levels due to diverse factors including inadequate financial and human resources along with lack of stability in political institutions, capacities of government machinery, and citizen awareness about rights. These major factors contribute towards the failure of local governance systems at lower tiers and as a result, poverty, with all its manifestations is still a big challenge for a larger population in the globe. Besides these factors, a centralized 
administrative approach in the developing world also aggravates this governance crisis.

Not an exception, in Pakistan, strong centralized bureaucratic control administers the whole governance system under a top-down approachNational Reconstruction Bureau (2000).During elections common masses are engaged in decision of their fortune but after elections people do not have any influence on their representatives in formulation of policies and planning for public welfare. This lack of interaction between political representatives, including bureaucracy and common masses results in non-participatory decision making, concentration of power, and non-transparent and less effective allocation and use of resources.

To address this problem of non-participatory top-down approach, decentralization and citizen's participation is most appropriate community mobilizing theme of present days, suggested by academia as well as international development organizations, particularly World Bank and United Nations (Leyland 1991) This approach offers local people not only an opportunity to govern themselves, but it devolves powers concentrated in some hands to many hands at the grass root level. This approach is associated with "economic efficiency, better accountability, larger resource mobilization, efficient service provision and fulfillment of local preferences" (Paracha, 2003).

Decentralization is considered as an effective tool to bring real development to rural communities as it ensures flow of resources from rich, urban communities to poor, rural communities Paracha (2003).Under the theme of decentralization in March 2000, a new government system "Local government Plan", also known as Devolution Plan, was introduced in Pakistan in March 2000 and came into effect from August 2001. This plan integrated government and bureaucracy in coherent structure answerable to elected representatives at district level. In this plan, a village was considered as a unit of community participation and Union Council (UC) was taken as unit for service delivery National Reconstruction Bureau (2000).

In the first decade of the new millennium, initially, Devolution Plan and then Poverty Reduction Strategy Paper 2003 fortified materialization of Citizen Community Boards (CCB) as a tool for devolution and poverty reduction through community participation Bowen, (2006).As an institution, a CCB was aimed an effective community participation at village level for transparent and efficient decision making, resource utilization, and public service delivery.

According to Devolution Plan, the main functions of CCB were "to enable proactive elements of society to participate in community work and development related activities in both rural and urban areas" National Reconstruction Bureau (2000). According to available data at the United Nations Development Programme, total number of CCBs formed in Pakistan during 2004 to 2010 was22,000. With an average of 25 members of each CCB, this institution could engage approximately 550,000 citizens in development processes throughout the country. If determined by 
number of CCBs formed and citizens engaged, effectiveness of these forums is less than expectations, and reflects issues to functionality of CCBs and consequently devolution of powers and community participation challenges for poverty reduction at grass root level (Mansuri \& Rao, 2004; Kurosaki, 2006; Ahmad et. al, 2015).

At Government's Social Welfare department records, total number of CCBs registered from 2003 to 2013 was 1,343. During this period According to available records, only $163 \mathrm{CCBs}$ could identify and initiate projects for their local development. The rest of the 1,180 CCBs could not propose or undertake any development initiative for their communities. This magnitude of non-functional CCBs stresses on the need to investigate and explore the issues and challenges to proper functioning of CCBs, and ultimately effective community participation for poverty reduction at the grass root level.

\section{Literature Review}

Historically, the term participation itself and as an approach, emerged in mid of 1970s as a result of a paradigm shift from capital centered development strategies to people centered development strategies Oakley (1995). This term was firstly introduced by various international level organizations including the United Nations, World Bank, International Labor Organization, and Overseas Development Administration Leyland (1991).

For first time, Economic and Social Council (UN 1975) recommended governments to adopt participation as policy measure for active involvement of individuals and national level non-governmental organizations. At the same time, International Labor Organization (1977) (as cited in Leyland 1991) considered participation as a basic need of people, and critical part of any development strategy.

Available literature lacks a single definition of participation instead it considers this term flexible in its nature. It is widely believed that the word participation can consist of other well defined elements therefore, there are many ways to define participation Leyland (1991).Another conception considers that based on its envisaged objectives set by different groups, participation as a concept has variations in its interpretations Paul (1987).Similarly, He considered community participation as a mean for local people to improve their living standards particularly income, personnel growth, and self-reliance by controlling direction of a development program. He added that community participation enables beneficiaries to initiate development projects, develop capacities for projects, improve effectiveness of projects, sharing of costs and project efficiency.

World Bank (1994)in its approach of Community Driven Development defined participation as a process of involvement of all stakeholders in initiating various development related works, controlling resources, and making decisions according to their priorities. It also added that community participation is important to reach poor. Oakley (1995) found evidence of a link between participation, 
economic growth and development at the national level. He also expected that participation can affect development performance of a country due to realization of people's potential, and an increase in opportunities to be efficient and effective with new ideas for their self-reliance. The results also pointed out that participation could result in less dissatisfaction of citizens toward their governments and development policies.

Taking another point of view different to traditional approaches, Chambers (1997) described participation as a process where "the positivist, reductionist, mechanistic, standardized-package, top-down models and development blueprints are rejected, and in which multiple, local, and individual realities are recognized, accepted, enhanced and celebrated"

Maharjan (2017) stated that, through law on Regional Governance, central government transferred all powers to local governments. Decentralization is expected to improve community participation, local capacity, accountability, transparency, responsiveness and the targeting accuracy of government programs.

Rahim and Shirazi (2018) evaluated the performance of local governments in Pakistan through citizen's satisfaction with local public service delivery in the framework of the 2001 devolution plan. The findings revealed that the devolution policy variable was found to be statistically significant, indicating that people's satisfaction level declined significantly when the devolution plan was rolled back. The impact of demographic and socio-economic variables on citizen satisfaction with local government is also statistically significant in a majority of cases.

\section{Historical Perspective of Citizen Participation in Pakistan}

In Pakistan, inclusion and participation of people for local development has been an area of numerous efforts by various governments since the 1960s. Surprisingly, the most significant work towards decentralization, a pre requisite for participation, was carried out during the military rules of General Ayub Khan, General Zia-ul-Haq and General Pervez Musharraf. For the first time in 1959, an alternative system at the grass root level evolved, as a result of local governments in the form of Basic Democracies. This system was introduced by President General Ayub Khan, particularly to form an electoral college to legitimize his election and political agenda. Although the lowest tier in this system was union council with full elected members, this system was under complete bureaucratic control at higher tiers. Instead of more inclusion and participation of people, this system could only provide a platform for local level elites to play their role, not for local development, but to form a "representational dictatorship" (Cheema et al., 2005).

Another local government system was introduced by General Zia-ul-Haq in 1979 after overthrowing a civil government. Though this system was also based on elections of community representatives at UCs and higher levels, but different to President General Ayub's Basic Democracies, this system empowered elected 
members as head of local councils. This provided more control and authority, resulting in reduced control of bureaucrats to some extent.

In March 2000, a new government system called "Local Government Plan", also known as Devolution Plan, was introduced in Pakistan and came into effect from August, 2001. This Plan introduced a new framework for the integration of local government and bureaucracy, this was expected that this coherence will result in more accountability of bureaucracy to elected representatives.

This system was based on five complementary Ds. Citizen monitoring was also introduced, which was led by the elected representatives. Furthermore, involvement of civil societies was enhanced to ensure transparency. One of the Ds, for instance, is diffusion of the power-authority nexus which is carried out through monitoring by citizens and elected representatives, civil society's involvement in development work, and effective checks and balances. The new power or governing structure consisted of three tiers associated with each other. In the Devolution Plan, a village was considered as a unit of community participation whereas a UC was taken as a unit for service delivery.

An important feature of this system is the recognition of community or civil society's role and participation. This role of general public is considered as a driving force for community empowerment and sustainable development. The Devolution Plan formalized formation of CCBs as the most effective approach for devolution and, consequently, poverty reduction. CCBs comprised of a general body with 25 non-elected individuals from local community. This general body nominated sevenmember executive body, including the chairman and secretary, for proper functioning of the CCB. According to the Local Government Ordinance, the main functions of a $\mathrm{CCB}$ were:

- Improvement of delivery of service by a public facility

- Development and management of a new public facility

- Welfare of the handicapped, destitute, widows, and families in extreme poverty

- Establishment of farming, marketing, and consumer's cooperatives

- Identification of development and municipal needs and mobilization of resources

- Formation of stakeholder associations (voluntary associations such as Parent Teacher Associations, Patient Hospital Associations, School Management Associations, Farm Water Associations, Citizen Police Associations, etc.) for community involvement in the improvement and maintenance of specific facilities.

- and, Reinforcement of capacity of a specific monitoring committee at the behest of the concerned council. 
CCBs were considered as a tool for building community empowerment, effective service delivery and social capital. Local citizens were given the power top ropose projects which were $20 \%$ funded by the local community and $80 \%$ by the local government. Working of CCB is elaborated by following flow-diagram.

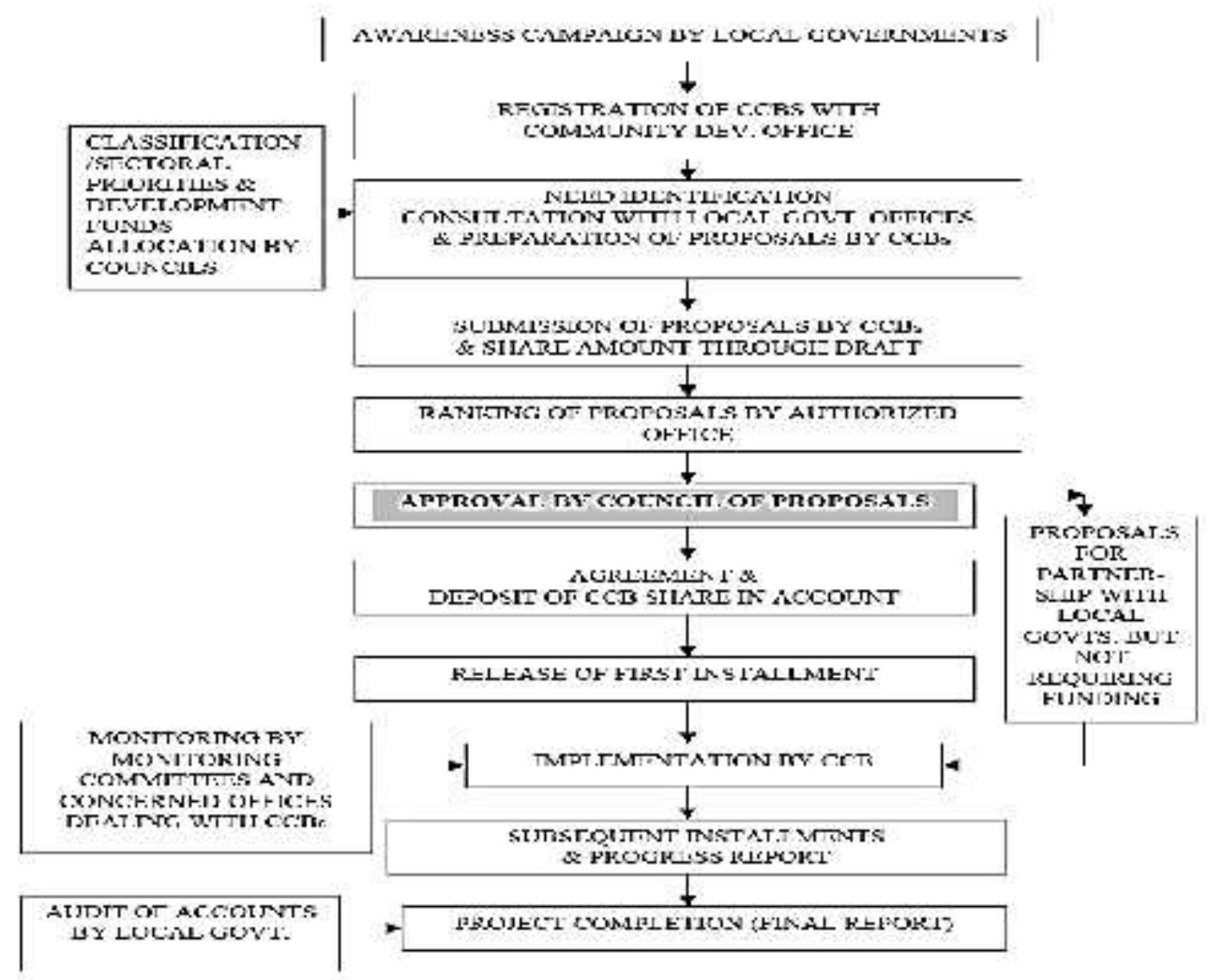

Figure 1: Flow diagram of CCB Project Initiation to Completion(NRB, 2000)

\section{Challenges to community participation}

Practicing community participation for development faces many challenges as identified in different streams of literature. Arnstein (1969) said that "informing citizens of their rights, responsibilities and options can be the most important first step toward legitimate citizen participation" (p. 219). However, too frequently the emphasis is placed on a one-way flow of information - from officials to citizens - with no channel provided for feedback and no power for negotiation. Under these conditions, particularly when information is provided at a late stage in planning, people have little opportunity to influence the program designed "for their benefit" (p. 216).

While discussing failures of local self-government, Quddus (1981) pointed out that poverty, wide spread ignorance about rights and duties of citizenship, laziness of educated classes, and partisanship of representatives are major reasons behind malfunctioning governance systems. He further added that local self- 
government aiming to build community participation is facing diverse problems including constitutional, administrative (due to prejudice of executives), operational, functional and financial issues. He summarized the impediments to local institutions as lack of democratic development, education, and active interest; absence of positive efforts by higher tiers of government; and much bureaucratic control.

In a study on participation of farmers for water management, Meinzen et al.,(2002)observed that villagers organize themselves to form and register an organization when its expected benefits are greater than its costs. In addition, physical and socioeconomic environment also affects participation. These factors include water availability and size of group, heterogeneity of group, market access, presence of other organization(s) and leadership. Under the Rural Communities Impacting Policy Project, mentioned seven potential barriers and challenges to individuals and community organizations for effective participation. These are lack of understanding of the policy process, lack of community resources, lack of access to information, reliance on volunteers, absence of rural representation and certain community groups in the decision-making process, working relationship between government and rural communities, and time and policy timeline restrictions Dukeshire and Thurlow (2002).

Bardhan, and Mookherjee (2000)argued in their theoretical work that initiatives for community participation may be vulnerable to captured by local elites due to their political interests. For this reason, communities lose trust in such forums and, consequently, powers again concentrate despite of devolution. Chohan (2007) in his study of CCBs concluded that although the concept of CCB is new, CCB is an effective and efficient organization made by the people for the benefit of people at the grass root level. Academics and civil society organizations criticized that much needed to be done for the projection of CCBs at the grass root level as there are certain areas where free flow of information is still lacking for citizens.

Kurosaki (2006) conducted research on CCBs in district Hafizabad of Punjab province in Pakistan. He observed that progress of CCBs and participation of community is below the satisfaction level. He raised the concern that Pakistani society has limited historical experiment that is why it is handicapped in CCB based development. He concluded in his study that the key to success of a CCB are rules within the CCB and leadership. He also suggested that capacity building of CCB and the local community is important for proper functioning. Moreover, he found that villages in UCs with the presence of non-governmental organizations in the UCs and influential persons in village, and with less access to schools and financial institutions are more likely to be successful in forming a CCB. According to him the determinants of successful CCB formation and functioning include the age of a CCB, strict management (regular meeting and record keeping), and technical skills (diversity in members' occupation).

In order to make CCB (or participatory development in general) more sustainable in terms of planning, implementing, and monitoring, He suggests to 
increase pro-poor components with active participation of the poor and landless. In other words, to make CCB type cooperation more effective in development, the heterogeneity of the local people (the depth of socioeconomic gap among classes), and the potential of civil society institutions such as non-governmental organizations and the local elite in mobilizing the people must be given attention. However, his study only focused on functioning CCBs and could not analyze the effects of same variables on non-functioning CCBs. In addition, his data set comprised of a small number of CCBs (77 CCBs) who drafted project proposals.

Building upon Kurosaki (2006)'s work, this paper examines the effects of different internal and external variables on functionality of CCBs taking both functioning and non-functioning cases. As internal variables this paper examines CCB type (by gender of its members), group size, ratio of female members, age, gender of chairman, and training. As external factors the present study investigates UC characteristics such as topography, distance to district headquarter, and number of total and functional CCBs in a UC. Moreover, turn out in the 2005 local elections as a proxy of trust level on the Devolution Plan, and contestants on councilor seats in a UC as a proxy for social and political activists in a UC, are also included.

\section{Material and Methods}

The present study focuses on two different categories of CCBs. Therefore, on basis of the scope of this study these categories are defined as follows.

(i) Functional CCB: A CCB which completed a project.

(ii) Non-functional CCB: A CCB which could not complete a project.

Our research compares same variables for functionality and nonfunctionality by taking both types of CCBs into account. According to records available at the Provincial Government's Social Welfare Department, the total number of CCBs formed in Abbottabad from2003 through2015was 1,343. All these CCBs were taken into considerations as the universe for the proposed study. Out of these CCBs, 163 were functional whereas 1,180 were non-functional CCBs. This study analyzed data for 1,065 CCBs, including 161 functional and 904 nonfunctional CCBs in 2017.

\section{Model}

As a CCB could be functional or non-functional, instead of a conventional ordinary least square model the present study analyzes CCB functionality by the following logit model.

$Y i=a+X i b_{1}+X j b_{2}+u i$ 


\section{Variables}

$Y i$ is the binary variable for $C C B i$ to initiate a development activity. Its value one indicates a functional CCB where as zero indicates a non-functional CCB.

$X i$ is a vector of CCB internal characteristics including variables of CCB age, number of members, gender of chairman, type, capacity building members by Devolution Trust for Community Empowerment, and ratio of female members.

Similarly, $X j$ is a vector of external characteristics of UCs including continuous variables for distance from district headquarter, number of councilors contestants in a UC level last local body election, turn out in last local body elections, number of other registered CCBs in UC, and binary variables for topography of UC and success ratio of other CCBs.

Whereas $\boldsymbol{b}_{\mathbf{1}}$ and $\boldsymbol{b}_{\boldsymbol{2}}$, are vectors of parameters for internal and external factors, respectively, to be estimated, and uiis the zero-mean error.

The effects of various variables are analyzed by a logistic regression model which takes CCB functionality as the dependent binary variable. In this variable a value of one represents a functional $C C B$ while a value of zero indicates a nonfunctional CCB. Functionality of CCB is analyzed by considering both internal and external variables in a logistics regression model.

\section{Results and Discussion}

\section{Results}

Descriptive analyses of 1,065 CCBs show that only 15\% (161) of CCBs could propose and carry out any local development project where as $85 \%$ (904) of CCBs remained non-functional. Moreover, 842 of these CCBs were male CCB whereas women formed 186 CCBs. In 390 CCBs both men and women have representation. CCB registration remained at a high point for the first five years of the Devolution Plan, but, surprisingly, declined drastically after 2008 when democracy was restored in the country. Only 243 CCBs were trained by external agencies for their project management skills. Total PKR 34 million of public resources were utilized by these CCBs who themselves contributed $21 \%$ of the share. The results of this analysis are given in following table.

Table 1

\section{Determinants of CCB Functionality}

\begin{tabular}{|c|c|c|c|c|}
\hline \multicolumn{2}{|c|}{ Logistic regression } & \multicolumn{3}{|c|}{ Number of obs $=1065$} \\
\hline LR chi2(20) & $=210.66$ & & & \\
\hline Prob > chi 2 & $=0.0000$ & & & \\
\hline Log likelihoo & $d=-347.01766$ & & & \\
\hline Pseudo R2 & $=0.2329$ & & & \\
\hline funct & Coef. & SE & $\mathrm{P}$ & 95\% Conf. Interval \\
\hline Success ratio & 7.534096 & .9544217 & $<.0001$ & 3.687683 \\
\hline
\end{tabular}




\begin{tabular}{llllll}
\hline CCB age & .0014172 & .0002758 & $<.0001$ & .0008723 & .0020214 \\
\hline Training of CCB & 1.661696 & .2015527 & $<.0001$ & 1.416587 & 2.288947 \\
\hline Group size & -.0823952 & .0417611 & $>.0001$ & -.5298941 & .3475087 \\
\hline cons & -6.09616 & 1.315604 & $<.0001$ & -10.64045 & -2.463116 \\
\hline
\end{tabular}

The estimation results show that among external factors presence of functional CCBs in a UC is statistically significant with a $p$ value $<.00$. A CCB belonging to a rural UC or an urban UC has equal likelihood of being functional or non-functional. Interestingly, distance of UC from district headquarter is also insignificant. From this it can be inferred that CCBs of areas close to the district headquarter are equally non-functional as CCBs of areas far from the district headquarter. Though turn out during local elections remained moderate $(53 \%$ on average), this trust on the local system could not further materialize in the form of CCB functionality. Likewise, presence of other CCBs in the area, social activists do not have an impact on CCB's functionality.

Considering internal factors of CCBs, female CCBs, female ratio, and gender of $\mathrm{CCB}$ chairman are not statistically significant on functionality of CCB. The variable group size has a $p$ value $=.048$ and positively affects $C^{C} B^{\prime}$ 's functionality. Similarly, age of a CCB is highly significant on $C^{2} B^{\prime}$ s functionality with ap value $<.00$. Similarly, training of CCB significantly contributed in functionality of CCBs.

\section{Discussion}

The presence of other organizations of similar nature in the community or village play a role in the formation of similar forums Kurosaki (2006). This study also confirms that success of other CCBs in neighboring areas have positive impact on functionality of a CCB. This could be attributed to a competitive environment among communities as well as improved access to information among CCBs related to various stages during project design and implementation. Although literature stresses that lack of access to information, difference between urban and rural communities, time restrictions, and relationship between government and rural communities make it challenging for communities to run their organizations (Chohan 2007; Dukeshire and Thurlow, 2002). This study finds that the variable of distance as well as area topography is not statistically significant on CCB functionality.

Despite the fact that literature considers turn out in local body elections, a proxy for trust levels, as an important pillar for effectiveness of local government systems Quddus (1981), the efforts of decentralization and devolution of powers could not remain highly effective as this study finds that turn out in a given UC does not has any statistically significance on functionality of CCBs in that area.

Analysis shows that presence of local social and political activists in a UC and functionality of CCBs are not statistically related to each other. This finding negates the proposition that local political elites and influential persons can play a 
pivotal role in local development process by motivating, networking, and patronizing initiatives of community participation (Bardhanand Mookherjee, 2000;Meinzenet al., 2002).Prior studies also consider that lack of financial resources is a constraint to proper functioning of local governments Quddus (1981), but analysis of these data show that fund mobilization at the UC level does not have any statistical significance on functionality of CCBs in that particular UC.

In terms of internal factors, available literature finds that smaller group size in community organizations improve better linkages among members. Bardhan (2000) also finds a statistically significant negative relationship between membership and CCB functionality. This finding confirms that larger group size results in more heterogeneity among CCB members in terms of age, experience, skills set as well as caste and ethnicity. This heterogeneity may result in both functionality and nonfunctionality due to different reasons. This study also confirms the findings of Kurosaki (2006)'s research, on 77 CCBs of Hafizabad district, that age of a CCB is significant on CCB functionality.

Literature repeatedly identifies "capacities of local people" both as an end as well as a means for larger participation Paul (1987). Lack of community awareness about government procedures as well capacities to initiate projects hinder the functionality of CCBs. Kurosaki (2006)in his empirical work also considers capacity building as an important determinant for CCB effectiveness. The findings of this study support the linkage between capacity building and functionality of CCB with a strong relationship between these two variables.

While the Devolution Plan encouraged female participation at the grassroots level by reserving seats for women in local bodies, due to cultural and social constraints participation of women remained very low in local councils Mezzera et al., (2010).Similarly, data of this study show that there are 80 CCBs formed by women out of which only 13 were functional. The regression analysis finds that there is no statistically significant relationship between gender of CCB members and functionality. Development projects carried out by CCBs are found very much consistent with the international development agenda known as Millennium Development Goals. Highest numbers of projects are carried out for improved access and supply of clean water. Vocational training also remained as a key area of interest for female CCBs to initiate and implement projects.

\section{Conclusion}

The CCB approach provided an opportunity for people to organize themselves and divert resources for poverty eradication through local development initiatives focusing on provision of basic services including clean water, roads, and income generation. This study finds that this approach for community participation to eradicate poverty is facing challenges in its functionality and did not work out as expected. Capacity building of CCBs and success of other neighboring CCBs contribute positively in CCB functionality, whereas it is also observed that CCBs took longer to be functional. On the contrary, it is found that both urban and rural 
areas do not affect CCB functionality, and CCBs near to the district headquarters, though having a comparative edge of easy access, are not equally functional. Trust of citizens on local government system could not make significant contribution to motivate CCB for its functionality. Similarly, gender issues are found as constraints to CCB functionality as female CCBs are less functional as compared to male CCBs. Presence of local political activists and funds mobilization in a UC through CCBs do not have a considerable impact on functionality of CCBs. Based on the findings of the study, the results recommend that Capacity building plays a pivotal role in allowing citizens to know about their rights as well as to carry forwards linkages with government line departments to initiate and implement local development projects. Therefore, it is highly recommended to pay sufficient attention to this factor particularly in terms of its scope and resources. Moreover, it is recommended to explore social and cultural constraints for female citizen participation. Female participation should be encouraged by all means as this would not only politically empower them, but their control over resources can be diverted for improvement in female employment potential. It is essential to further investigate the causes of low community participation in areas close to district headquarters as well as how role of political activists can further be enhanced. 


\section{References}

Ahmad, Z. Khalid, I. \& Muzaffar, M. (2015). An Analysis of the Relationship Between Local and Provincial Governments in Pakistan (2001-2009), Journal of Political Studies, 22 (1), 63-74

Arnstein, S. R. (1969). A ladder of citizen participation. Journal of the American Institute of planners, 35(4), 216-224.

Bardhan, P. (2000). Irrigation and cooperation: An empirical analysis of 48 irrigation communities in South India. Economic Development and cultural change, 48(4), 847865 .

Bardhan, P. K., \& Mookherjee, D. (2000). Capture and governance at local and national levels. American economic review, 90(2), 135-139.

Bowen, G. A. (2008). An analysis of citizen participation in anti-poverty programmes. Community development journal, 43(1), 65-78.

Chambers, R., (1997).Whose reality counts? Putting the first last. London: Intermediate Technology Publications, P.188.

Cheema, A., Khawaja, A. I., Qadir, A., (2005). Decentralization in Pakistan: Context, content and causes (Faculty Research Working Paper Series RWP05-034). Cambridge: Harvard University, p.1-41.

Chohan, A. (2007). Role of Citizen Community Boards for local development under Punjab Local Government Ordinance (2001), Pakistan. In 43rd ISOCARP Congress.P.1-17.

Dukeshire, S., \& Thurlow, J. (2002). Rural communities impacting policy challenges and barriers to community participation in policy development. Dalhousie University. P.1-14.

Growth, A. E. (2003). The road ahead (Poverty Reduction Strategy Paper). Ministry of Finance, Government of Pakistan.

Kurosaki, T. (2006). Community and economic development in Pakistan: the case of Citizen Community Boards in Hafizabad and a Japanese perspective. The Pakistan Development Review, 575-585.

Leyland, T. (1991). Participation in the 80's and 90's: Who Asks the Questions in Livestock Development (Doctoral dissertation, Centre for Tropical Veterinary Medicine, University of Edinburgh). p.1-51

Maharjan, K. L. (2017). Decentralization: potential and challenges for rural development. In Decentralization and Rural Development in Indonesia (pp. 13-26). Springer, Singapore. 
Mansuri, G., \& Rao, V. (2004). Community-based and-driven development: A critical review. The World Bank Research Observer, 19(1), 1-39.

Meinzen-Dick, R., Raju, K. V., \& Gulati, A. (2002). What affects organization and collective action for managing resources? Evidence from canal irrigation systems in India. World development, 30(4), 649-666.

Mezzera, M., Aftab, S.,\& Yusuf, S. (2010). Devolution row: an assessment of Pakistan's 2001 local government ordinance. Report for the research project: "The 'Political Economy 'of State-building-The Pakistan Case Study", Netherlands Institute for International Relations, The Hague, P.1-44.

National Reconstruction Bureau (2000). The Local Government Plan 2000.

Oakley, P., (1995).People's participation in development projects, (Vol .7). Oxford: Intrac, $.7: 1-40$

Paracha, S. A., (2003). Devolution Plan in Pakistan: Context, implementation and issues. Open Society Institute, Budapest-Hungary, P.1-71.

Paul, S., (1987). Community participation in development projects. Washington, DC: World Bank.

Quddus, S. A., (1981).Local self-government in Pakistan. Lahore: Vanguard Book Ltd. P.75.

ur Rahim, F., \& Shirazi, N. S. (2018). Fiscal decentralization and citizen's satisfaction from local public service delivery in Pakistan. International Journal of Ethics and Systems, 34(1): 122-142.

World Bank, (1994). The World Bank and Participation (Working Paper 13726).Washington, DC: World Bank. 